\title{
Sobre a noção de desenvolvimento baseada na felicidade: consideraç̃oes críticas
}

\author{
José Marcos Froehlich* \\ Mauro Barcellos Sopeña**
}

\section{Resumo}

A crítica ao desenvolvimentismo tem levado a uma busca por novas atribuições de sentido à noção de desenvolvimento. Recentemente, um conjunto de trabalhos tem associado o desenvolvimento à noção de felicidade. Neste artigo, empreende-se uma análise de tal associação a partir da interpretação freudiana sobre a relação entre indivíduo e sociedade, principalmente aquela apresentada na obra clássica O mal-estar na civilização, de 1930. Assim, o que se apresenta neste trabalho envolve necessariamente (a) uma relativização da noção de felicidade baseada em indicadores; e (b) um contraste entre a nova proposta e o sentido que a noção de desenvolvimento assume em diferentes abordagens teóricas. Conclui-se que o esforço de reformar os indicadores de desenvolvimento não apresenta avanços conceituais significativos, senão mecânicos ou matemáticos. Ademais, a contribuição de Freud sobre o trade-off entre psiquismo humano e cultura não está contemplada criticamente na discussão dos novos indicadores.

Palavras-chave: Desenvolvimento, Felicidade, Índice de felicidade futura, Freud, Felicidade interna bruta.

* Universidade Federal de Santa Maria. Santa Maria, RS, Brasil.

**Universidade Federal do Pampa. Santana do Livramento, RS, Brasil. 


\section{On the concept of development as happiness: a critical approach}

\section{Abstract}

Criticism on developmentalism has led to a search for new meanings to the concept of development. A series of studies have recently associated development with the notion of happiness. In this article we analyze this association based on the Freudian interpretation of the relationship between individual and society, especially that presented in Freud's classic work Civilization and its Discontents of 1930. Thus, what we argue in this paper necessarily involves (a) a relativization of that notion of happiness based on indicators; and (b) a contrast between the new proposal and the sense carried by the concept of development in different theoretical approaches. The analysis showed that efforts to reform development indicators did not accomplish significant conceptual advances, but rather mechanical or mathematical. In addition, Freud's contribution to the trade-off between human psychism and culture is not critically incorporated in the discussion on new indicators.

Keywords: Development, Happiness, Index of future happiness, Freud, Gross domestic happiness.

\section{Introdução}

Ora, existe um sobressalto instantâneo que desperta dos sonhos infantis. Pois que segurança é esta que observo aqui? Posso, depois das experiências que realizo aqui fora, avaliar o perigo que corro dentro da construção?

Os meus inimigos têm o faro certo, quando não estou nela? Certamente eles têm algum faro de mim, mas não todo.

(Kafka, 1998, p. 76)

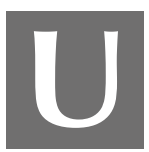

ma crítica ao Produto Interno Bruto (PIB) como indicador seguro da realização fática da complexa noção de desenvolvimento mostrase central no programa sustentado pela noção de felicidade interna bruta ${ }^{1}$. A origem deste conceito hedônico está relacionada a experiências realizadas no Butão, desde a década de 1970, e atualmente conta com o apoio do Programa das Nações Unidas para o Desenvolvimento (PNUD), considerando um conjunto de indicadores: (a) uso do tempo; (b) educação; (c) meio ambiente; (d) padrão de vida; (e) bem-estar psicológico; (f) saúde;

\footnotetext{
${ }^{1}$ Referências ao conteúdo deste programa estão aqui citadas pela indicação FIB (FIB, 2013).
} 
(g) vitalidade comunitária; (h) cultura e (i) governança (FIB, 2013). Embora se possa caracterizar tal iniciativa ainda como de caráter emergente e relativamente pouco difundida em círculos acadêmicos, nota-se que a noção de felicidade vem sendo crescentemente acionada em estudos socioeconômicos e instituições preocupadas com o desenvolvimento, como demonstram os trabalhos recentes de Neri $(2008 ;$ 2011), do IPEA e da FGV, e mesmo em instâncias políticas e estatais, como atesta a criação, na Venezuela, em 2013, de um Vice-Ministério da Suprema Felicidade Social.

Nesse contexto, são apresentadas argumentações acerca da possibilidade de criação de indicadores sistêmicos capazes de mensurar o progresso de uma região, representando, assim, a "meta e o propósito do desenvolvimento" de uma nova governança, complementar ao PIB e reivindicatória quanto à sua reconstrução (FIB, 2013). O desenvolvimento tem sido uma pauta histórica das ciências sociais e econômicas, mas particularmente esta última tem sido historicamente mais refratária a vincular noções demasiado imersas em subjetividade aos sentidos do desenvolvimento. Todavia, segundo Franco (2011, p. 3), avanços teóricos e empíricos recentes têm contribuído para que os economistas iniciassem uma nova reflexão sobre a felicidade, ou sobre o que há de humano na disciplina; e, em particular, para que se revisassem as defesas construídas no decorrer do tempo para impedir que a economia invadisse ou se deixasse invadir pela psicologia; ou sobre cogitações sobre o que, afinal, significa, em termos empíricos, a satisfação com a vida.

Em trabalho de Antolini (2016), argumenta-se que a felicidade não foi levada em consideração nos sistemas de contas nacionais, muito embora, em tempos recentes, a inclusão da felicidade em agregados econômicos é uma questão em voga na agenda sociopolítica que busca usar estudos sobre a felicidade para analisar o impacto de modelos de desenvolvimento econômico na vida das pessoas - dadas suas preferências. Mas este movimento não está isento de polêmicas. Em trabalho recente, ao refletir sobre progresso e desenvolvimento econômico, Bresser-Pereira (2014) descarta a possibilidade de que esta noção possa servir para medir bem-estar social, argumentando que não é algo que possa ser alcançado coletivamente. 
Embora Bresser-Pereira (2014) não aponte, o argumento de que a felicidade é um estado individual, eminentemente subjetivo e transitório, encontra em Freud um de seus principais defensores. Assim, realizamos aqui uma análise do conjunto de proposições recentes sobre indicadores de felicidade, a partir da interpretação freudiana. Para esta tarefa, faz-se uso, principalmente, das reflexões de Freud apresentadas no seu texto clássico, O mal-estar na civilização, de 1930 (2010). Portanto, o que a seguir se apresenta envolve necessariamente (a) uma relativização daquela noção de felicidade baseada em indicadores; e (b) um contraste entre a nova proposta e o sentido que a noção de desenvolvimento assume em diferentes abordagens teóricas. De forma crítica, o artigo faz emergir uma dúvida: por que razão a reflexão freudiana não é criticada naquelas abordagens que se utilizam da felicidade ao tratar da noção de desenvolvimento? Seria de se esperar que a pretensão de tomar a noção de felicidade (seja a FIB ou outro conjunto de indicadores) como parâmetro para medir bem-estar social, desvinculada de variações individuais e da transitoriedade dos estados individuais de felicidade, dialogasse criticamente com reflexões reconhecidas nas ciências humanas que questionam esta possibilidade. Uma destas reflexões mais fundamentais é a de Freud, para quem a felicidade é um estado essencialmente transitório e subjetivo pela própria relação que o indivíduo estabelece com a sociedade; desconstruir criticamente os argumentos de Freud a respeito, e não ignorá-los, deveria ser uma tarefa das abordagens que vêm se utilizando da noção de felicidade como ressignificação para a noção de desenvolvimento.

Portanto, temos claro que a análise crítica dos indicadores do desenvolvimento é um tema muito sensível e relevante atualmente. Dessa forma, abordar as teorias e políticas de desenvolvimento que buscam correlacionar econometria com noções de felicidade, à luz das reflexões de Freud sobre os atributos e sentidos desta noção eminentemente sentimental e subjetiva, são desafios bem contemporâneos para as agendas das políticas sociais e das epistemologias que buscam contemplar a interdiciplinaridade na produção de conhecimentos. Nesse sentido, pretendemos contribuir, 
mesmo que modestamente, ao pertinente debate sobre as interações entre sociologia e psicanálise, ainda muito pouco contemplado no Brasil.

Assim, o presente artigo conta com esta introdução, com uma análise de como a noção de felicidade tem sido acionada no âmbito das discussões sobre o desenvolvimento, com a abordagem freudiana do fenômeno e, por fim, com as considerações finais deste ensaio.

\section{Felicidade e desenvolvimento}

Em conferência internacional sobre a FIB, o Primeiro Ministro do Butão destacou o quanto considera profícuo este programa. Curiosamente, em seu discurso podem ser identificados elementos importantes que também são mencionados ou postulados em estudos e reflexões sobre o que se reconhece como a atual abordagem territorial do desenvolvimento, com muitos escritos estabelecendo interfaces e correspondências terminológicas a respeito. Exemplarmente, nesse sentido, a descentralização, enquanto política de cunho territorial, é uma noção com presença frequente em várias abordagens sobre o tema (Souza, 1997; Bagnasco, 2001). Ademais, esta descentralização pressupõe um grau de consciência comum entre atores territoriais, que dispõe e facilita a cooperação e o comprometimento convergente, capaz de sinergias, elementos estes que estão em plena correspondência com o comportamento cívico igualmente abarcado (e esperado) por esta abordagem (Putnam, 2003; Abramovay, 2007). O excerto abaixo, extraído do discurso sobre o FIB (2013), ilustra esta pretensa interconexão entre as abordagens:

É muito encorajador observar como que aspectos do FIB estão sendo implementados de baixo para cima, de uma forma não centralizada, em muitas comunidades locais ao redor do mundo. Grandes mudanças de governos em prol do reconhecimento daquilo que seja o verdadeiro progresso, e de como este deve ser medido, podem de fato somente acontecer quando cidadãos e organizações, dispersos como são, agem em uníssono e convergentes, impulsionados por uma nova consciência (FIB, 2013). 
A amplitude do discurso envolve ainda questões de sustentabilidade, notadamente quanto à defesa de ações contrárias ao consumismo desenfreado, à injustiça com as gerações futuras e com o meio ambiente. Em trabalho de Tideman (2016), recortes relacionados à inter-relação de economia, sociedade e ecossistemas são apontados como importantes no programa da FIB. Ademais, a governança é indicada para servir à felicidade social, sobretudo nesta perspectiva ambiental guiada pela liderança em sustentabilidade. Em conjunto, esta problemática também é, com muita frequência, encontrada em importantes trabalhos sobre desenvolvimento sustentável (Veiga, 2005; 2010; Cechin, 2008). O enunciado a seguir é bastante ilustrativo nesse sentido:

Enquanto que essa augusta reunião discute o tema da prática e da mensuração do FIB, eu convido vocês para que ponderem as muitas perguntas que me assombram. [...] Como poderemos persuadir as pessoas para que adotem um novo paradigma ético que rejeite o consumismo? Como poderemos convencê-las de que o paradigma de crescimento ilimitado num mundo finito não é apenas insustentável e injusto com as futuras gerações, mas também espreme para fora as nossas buscas sociais, culturais, estéticas e espirituais? [...] As crises financeira, energética e alimentícia, bem como as calamidades naturais com magnitudes e frequências jamais vistas, creio eu, soam os sinais de alarme para nos avisar que devemos nos afastar do modo de vida que temos até agora adotado (FIB, 2013).

Há um explícito conteúdo prescritivo existente em boa parte dos textos, inclusive no sentido de tutelar a vida, a fim de cumprir os propósitos prescritos no discurso do desenvolvimento. Efeitos desta abordagem acerca da felicidade também são observados empiricamente em diversas latitudes. Feijó et al. (2012, p. 44) comentaram a criação por Sarkozy, na França, da Comissão para Mensuração do Desempenho Econômico e do Progresso Social para esclarecer as limitações do PIB como instrumento para medir os resultados econômicos e do progresso social, e elaborar instrumentos alternativos. A incorporação da noção de felicidade como tarefa do Estado desdobra-se na criação, na Venezuela, em outubro de 2013, de um ViceMinistério da Suprema Felicidade Social. O sentido de gerenciar programas 
sociais materializa-se na intenção de que as pessoas sejam "atendidas da forma mais sublime, sensível, delicada e amável".

A este respeito, Greve (2013, p. 170) observa que

A felicidade interna bruta tem sido um tipo alternativo de medida para analisar o desenvolvimento de uma sociedade. O Canadá possui até uma lei, o Ato de Medição do Bem-Estar, que tem como objetivo a publicação de informações acerca "do bem-estar econômico, social e ambiental das pessoas, das comunidades e dos ecossistemas do Canadá" [...]. Na Nova Zelândia, há um ministério cuja responsabilidade é pesquisar o bem-estar da sociedade [...]. Na França e no Reino Unido [...] tem havido um crescente interesse por outros tipos de medidas de desenvolvimento social. As Nações Unidas desenvolveram outros tipos de índices [...]. Além disso, a OCDE cada vez mais tem usado e apresentado dados sobre o bem-estar e outros indicadores não monetários. Isso mostra que a discussão não é apenas acadêmica, mas também está relacionada à tomada de decisões.

Um olhar panorâmico sobre as teorias do desenvolvimento bastaria para rejeitar argumentos que tomam uma sociedade como desejante de um poder superior que a direcione para um mundo melhor. A tutela não representa, para a literatura crítica sobre o desenvolvimento, uma condição adequada e coerente (Furtado, 1974; Cowen; Shenton, 1996; Crush, 1996). No entanto, o discurso do Presidente do Centro para os Estudos do Butão, fundado pelo PNUD, parece conter esta disposição:

Se o planejamento governamental, e portanto as condições macroeconômicas da nação, forem adversos à felicidade, esse planejamento fracassará enquanto uma meta coletiva. Os governos precisam criar condições conducentes à felicidade, na qual os esforços individuais possam ser bem-sucedidos. A política pública é necessária para educar os cidadãos sobre a felicidade coletiva. As pessoas podem fazer escolhas erradas, que por sua vez podem desviá-las da felicidade. Planejamentos de política pública corretos podem lidar com tais problemas, e reduzi-los, impedindo assim que ocorram em larga escala (FIB, 2013).

O entendimento desta crítica passa pela constatação da incapacidade que os indicadores econômicos convencionais apresentam em mensurar 
agregados econômicos e sociais. Kahneman e Krueger (2006) reconhecem este esforço, porém são relutantes ao propósito deste empreendimento

[...] the Kingdom of Bhutan has proclaimed the goal of measuring Gross National Happiness, and other governments, including the United Kingdom and Australia, are committed to producing national measures of subjective well-being. A measure of Gross National Happiness would seem to us to be an overly ambitious goal in view of the present state of knowledge and limitations of subjective measurement (Kahneman; Krueger, 2006, p. 20)².

No caso do PIB, sua capacidade é limitada ao cálculo do produto, medida esta que pode ser elaborada de quatro diferentes formas pela contabilidade nacional. Por sua limitação, fica evidente que não se apresenta como indicador completo que possa ser tomado como sinalizador do desenvolvimento. Nem mesmo quanto ao crescimento do produto se pode isso afirmar, bastando verificar que, por sua composição ${ }^{3}$, elementos subjetivos são descartados (como, por exemplo, o trabalho não remunerado) e qualquer gasto gera aumento de seu nível (gastos públicos realizados em casos de catástrofes, por exemplo, aumentam o PIB). Em uma economia fechada, o Produto Interno Bruto é calculado como segue:

$$
\mathrm{PIB}=\mathrm{C}+\mathrm{I}+\mathrm{G}
$$

onde, $\mathrm{C}=$ consumo das famílias; I = investimentos privados; $\mathrm{G}=$ gastos do governo.

Esta fórmula representa a abordagem dos gastos. Considerando as identidades matemáticas do cálculo, o PIB pode ainda ser calculado pela abordagem da renda (a) quando se realiza a soma dos pagamentos dos

\footnotetext{
2 [...] o reino do Butão proclamou a meta de mensurar a Felicidade Interna Bruta, e outros governos, inclusive Reino Unido e Austrália estão empenhados na produção de indicadores nacionais de bem-estar subjetivo. Uma medida da Felicidade Interna Bruta parece-nos um objetivo demasiadamente ambicioso, tendo em vista o conhecimento e as limitações atuais de mensurações subjetivas (Kahneman; Krueger, 2006, p. 20).
}

3 Para interpretação matemática do cálculo, ver, por exemplo, Vasconcellos (2008). 
fatores de produção (terra, capital e trabalho) ou (b) pela soma do valor adicionado (agregado) em cada uma das etapas da produção. Por fim, a quarta forma de se obter o valor deste indicador passa pela soma dos preços finais de bens e serviços. Todas as formas produzem o mesmo resultado monetário. Uma discussão acessória, porém fundamental aqui, refere-se ao sentido similar que é muitas vezes atribuído aos conceitos de crescimento econômico (PIB) e desenvolvimento econômico. Este último, na literatura econômica convencional, ocorre como desdobramento (estrutural) do primeiro. Assim, dado o crescimento econômico, pode-se esperar desenvolvimento, ou seja, pode-se esperar um ganho estrutural. Bresser-Pereira (2014, p. 55) comenta esta questão da seguinte maneira:

Na literatura econômica, desenvolvimento econômico e crescimento econômico são normalmente usados como sinônimos. No entanto, alguns economistas fazem uma distinção entre desenvolvimento econômico (que envolveria mudança estrutural) e crescimento econômico (que não envolveria). Acredito que [...] esta discussão não tem muito sentido. Os casos em que há crescimento da renda per capita sem mudança estrutural são a exceção, não a regra.

Diante dessas considerações, uma revisão muito mais conceitual do que econométrica parece urgente. O FIB promete esta reavaliação, por meio de três objetivos que avançariam em termos econométricos: (a) construir um novo índice, abrangente e sistêmico; (b) reavaliar o PIB em seu conjunto e (c) promover uma nova interpretação que permita transformar o FIB em um catalizador de mudanças.

Somam-se a esta discussão trabalhos recentes que versam sobre a construção e o emprego do índice de felicidade futura (IFF). Dois textos são aqui tratados: Índices de Felicidade e Desenvolvimento Econômico, de 2011 e Jovens, Educação, Trabalho e o Índice de Felicidade Futura, de 2008. Nesta última obra, Marcelo Neri apresenta resultados da aplicação deste 
indicador ao caso brasileiro ${ }^{4}$, não tratados especificamente aqui, senão por seu conteúdo conceitual. A pesquisa mostra-se sensível ao conjunto de elementos destacados na abordagem do FIB. Nota-se que, na coleta de informações,

Pergunta-se diretamente sobre subjetividades individuais e coletivas; sejam locais, nacionais ou globais. Permitindo mergulhar sobre como as pessoas formam suas aspirações, atitudes e expectativas, começando o longo questionário pelo nível percebido de felicidade pelo entrevistado, passando por avaliações sobre a situação do sistema educacional nacional chegando a avaliações sobre a economia local das cidades onde vive o entrevistado (Neri, 2008, p. 10).

O conjunto de variáveis apresentado no estudo é amplo e o uso de modelos intertemporais é realmente mais promissor do ponto de vista econométrico. A despeito da crítica que se possa realizar, é justo aqui entender e destacar que o tratamento econométrico deste fenômeno (ou de outro qualquer de natureza subjetiva) é realizado por muitos pesquisadores. Em estudo recentemente conduzido por Rojas (2015), o surgimento de novos indicadores de desenvolvimento calcados na mensuração da felicidade é notório. Ademais, segundo a autora, muitas das dimensões presentes naqueles índices correspondem a deveres próprios do Estado. Assim, baseando-se em elementos da obra de Amartya Sen, sinaliza sua conclusão central, como segue:

[...] a felicidade, base para a aferição do desenvolvimento de um país, é um dever do Estado, não cabendo falar na subsidiariedade deste sem que se configure afronta ao texto constitucional, à eliminação das principais privações à liberdade e óbice ao desenvolvimento nacional. [...] Dentre esses indicadores encontra-se o FIB - Felicidade Interna Bruta que possui nove dimensões, dentre as quais, saúde, meio ambiente, educação, por exemplo. Claramente identifica-se dentre essas dimensões, deveres impostos ao Estado quanto à sua garantia. O desenvolvimento deve buscar ainda a liberdade e, para tanto, mostrou-se necessária a remoção das principais fontes de privação daquela. Dentre estas fontes de privação, encontrase a omissão do Estado quanto a deveres que lhe foram impostos pela

${ }^{4}$ A aplicação deste indicador ocorre em 132 países (IFF - future felicity index) com questionário padrão, tendo o Brasil como líder no ranking de felicidade futura, com média 8,78 em uma escala de 0 a 10 (NERI, 2008). 
Constituição Federal de 1988. Dessa maneira, foi possível concluir que o Estado deve atuar para que o país possa desenvolver-se a partir dos novos índices de medição, postura incompatível com a subsidiariedade do Estado (Rojas, 2015, p. 12).

A autora, ao defender esta nova abordagem, associa os novos índices ao papel do Estado, argumentação que potencializa a utilização daqueles indicadores e coloca em questão, ao menos potencialmente, o sentido de tutela. A novidade econométrica disposta a medir a felicidade, portanto, é considerada possível e inquestionável. A possibilidade, assim, está dada nesta abordagem, não restando sequer intenção de depurá-la em termos conceituais.

Como visto, a defesa da felicidade como indicador de desenvolvimento tem encontrado espaço em diferentes áreas do conhecimento. Nas ciências sociais, sobretudo, diversos estudos estão sendo conduzidos. No aludido trabalho publicado por Greve (2013), a utilização deste conceito deve ser elaborada a partir de uma abordagem multidisciplinar que envolva, ao menos, quatro grandes áreas do conhecimento: sociologia, economia, psicologia e filosofia. Alguns registros são centrais nesta obra: (a) indicadores econômicos são insuficientes para a medição do bem-estar social; (b) a formulação de políticas públicas deve levar em conta o nível de felicidade dos cidadãos; (c) a abordagem baseada na felicidade é inovadora do ponto de vista da compreensão das sociedades contemporâneas e (d) a medição da felicidade é factível. Neste contexto interpretativo, uma correspondência entre o nível de felicidade da sociedade e a atuação do Estado, segundo o autor, "é uma situação duplamente boa: o indivíduo se torna mais feliz e fica mais barato para o Estado de bem-estar social atuar." (Greve, 2013, p. 27).

Os contornos e pressupostos do referido estudo não deixam dúvida quanto à posição do autor, ou seja, ela se sustenta na noção de que a felicidade deve ser tomada como indicador. Assim,

O desejo humano por felicidade, do qual o hedonismo também é uma expressão, é importante para se entender por que a pesquisa sobre felicidade 
pode nos colocar no caminho para a boa sociedade, vista tanto pelo âmbito individual como pelo da sociedade (Greve, 2013, p. 48).

Observa-se, ainda, que o estudo de Greve considera promissora a mensuração da felicidade, sobretudo quando se apoia em pesquisas já realizadas sobre o tema. $\mathrm{O}$ autor considera que a validade dos estudos é geralmente alta. A este exemplo, argumenta da seguinte maneira:

Muitos estudos sobre o que afeta o bem-estar indicam que $80 \%$ das diferenças de felicidade entre nações e entre indivíduos podem ser explicadas por seis fatores: divórcio, desemprego, confiança, ser membro de uma organização religiosa, fé em Deus e qualidade do governo (Greve, 2013, p. 80).

Greve defende abertamente sua crença na capacidade de medição da felicidade, ressaltando, no entanto, um problema essencial desta medição, ou seja, a endogeneidade existente ou causalidade que impede qualquer relação segura de causa e efeito que a noção de felicidade possa expor ao pesquisador. Com base nesta ressalva, Greve (2013, p. 107) entende que

Somos capazes de medir a felicidade. Apesar de que existem e existirão problemas metodológicos quando se tenta estudar o nível de felicidade das pessoas, essas dificuldades não são maiores do que as enfrentadas em outros tipos de coleta de dados e análises que tentam retratar situações individuais. A capacidade de precisão pode, na verdade, ser maior do que em entrevistas qualitativas, embora estas forneçam outros tipos de informação.

O desfecho do trabalho de Greve concentra-se na defesa do indicador de felicidade como elemento constante na formulação de políticas sociais. Ademais, defende-se que os medidores clássicos de desenvolvimento não atendem plenamente questões relativas à sustentabilidade e bem-estar. Novos indicadores, amplos, combinados entre si e vinculados à noção de felicidade são, portanto, vislumbrados pelo autor como uma possibilidade. O propósito de avançar do ponto de vista econométrico parece presente em sua argumentação. 
Embora se observem invariavelmente limitações de natureza conceitual, mormente fruto de pressupostos irreais, o reconhecimento dos trabalhos científicos produzidos pela econometria não pode ser desprezado. No entanto, bastaria um olhar en passant sobre boa parte da teoria econômica para verificar o quanto seus modelos carecem de realismo quando se esforçam em modelar matematicamente seus objetos de estudo (Marques Junior; Pôrto Junior, 2003; Kahneman; Krueger, 2006). Em trabalho recente, Franco (2011, p.1) retrata com muita propriedade esta tendência a pressupostos irreais ao assinalar que

Os economistas sempre buscaram afastar-se do desafio de compreender a natureza da satisfação derivada do conforto material, talvez pela necessidade inicial de melhor estabelecer o distanciamento de disciplinas como a filosofia e a psicologia, ou ainda pela comodidade em permanecer numa região repleta de teoremas e equações, e com intermináveis afinidades instrumentais com a matemática.

No referido trabalho, o autor realiza uma defesa daqueles programas que se utilizam dos índices de felicidade para melhor compreender o desenvolvimento, negando a capacidade do PIB como indicador de crescimento e desenvolvimento. Em sua sustentação teórica, apresenta a dificuldade histórica que a ciência econômica enfrentou, inclusive em termos de distanciamento das questões sociais e ênfase na racionalidade. Segundo o autor, este animal humano

metamorfoseou-se numa criatura composta apenas a partir de axiomas definidores de "racionalidade", e o assim criado homo economicus tornouse um paradigma, uma entidade maximizadora de seus próprios interesses e a disciplina amadurece sob o signo do egoísmo e do paradoxo. Não é a virtude que produz a prosperidade das nações, mas indivíduos que buscam satisfazer seus próprios interesses. Conforme a duradoura lição de Adam Smith (1776, p. 18): "Não é pela benevolência do açougueiro, cervejeiro ou padeiro que podemos esperar nosso jantar, mas pela consideração que eles têm pelo seu próprio interesse. Não apelamos para sua humanidade, mas para seu egoísmo, e nunca lhes falamos sobre nossas necessidades, mas das vantagens que terão." (Franco, 2011, p. 2). 
$\mathrm{O}$ artigo permite verificar que a reavaliação dos indicadores convencionais de crescimento e desenvolvimento, tais como o PIB, foi resultado do crescente entendimento de que (a) não há correlação positiva entre felicidade e progresso material que se possa definitivamente comprovar; (b) o IDH ainda é insuficiente ao não contemplar a diversidade de elementos (não econômicos) que o desenvolvimento abarca; e (c) que as questões ambientais importam. Feijó et al. (2012, p. 45) sintetizam este caminho ao afirmarem que

em função da constatação de que o crescimento econômico não necessariamente significava progresso social (especialmente melhor distribuição da riqueza), passou-se a utilizar a denominação desenvolvimento econômico e social, o social ganhando proeminência em relação ao econômico. Daí a construção de todo um sistema de indicadores sociais, e o prestígio do IDH (Índice de Desenvolvimento Humano). Num terceiro momento, a questão ecológica ganhou relevância e, então, a expressão desenvolvimento sustentável surgiu, o ambiental ganhando proeminência em relação ao social e ao econômico. Assim, hoje há consenso de que o progresso deve ser ao mesmo tempo econômico, social e sustentável e, como consequência desta abordagem mais holística, alguns termos passaram a aparecer com mais frequência nas discussões atuais, como o conceito de bem-estar. $\mathrm{E}$, como que de forma a expressar de uma maneira mais abrangente o objetivo a que as sociedades deveriam almejar, a noção de felicidade passou também a ser mencionada com frequência. Daí os esforços no sentido da elaboração de indicadores de desenvolvimento sustentável, de bem-estar e de felicidade embora, nestes casos, não haja um indicador considerado consensual e amplamente aceito como é o caso do PIB, devido a divergências conceituais, dificuldades de mensuração e não disponibilidade de informações estatísticas apropriadas.

Em recente estudo de base econométrica, realizado por Ribeiro (2015), esforços são conduzidos para a inclusão de bens relacionais à análise usualmente embasada na renda como determinante da felicidade (perspectiva material do fenômeno). Por bens relacionais, segundo entendimento do autor, relações sociais estão incluídas na análise e na determinação do grau de felicidade do povo brasileiro e se referem a elementos como casamento, religiosidade ou amizade. A subjetividade do conceito é indicada pelo autor como segue: 
Apesar destes enormes esforços intelectuais não há consenso sobre o que seja a felicidade. Uma alternativa analítica é pedir para cada indivíduo dizer se é ou não feliz. Assim seria possível compilar essa informação para definir o grau de felicidade, ou bem-estar percebido, de populações inteiras. De fato, é exatamente por ser tão difícil definir a felicidade que um grupo de sociólogos, economistas e psicólogos acredita que a melhor maneira de estudar o tema é perguntar às pessoas que compõem a população o quanto são felizes (Ribeiro, 2015, p. 38).

O que se depreende do estudo é que os avanços em termos de medição realizados pelo autor permitiram apontar certos pontos contextuais de sociabilidade que são tão importantes para os cálculos de variação da felicidade quanto aqueles de ordem puramente material. $\mathrm{O}$ avanço em termos de mensuração não enfrenta, no entanto, uma questão que parece central: a noção de felicidade, tomada apenas como uma variável dependente do modelo. Em adição, conforme assumido pelo próprio autor, problemas de endogeneidade impedem qualquer relação de causa e efeito que o sentido estrutural da felicidade possa apresentar.

Diante dessa evidente subjetividade, um recurso utilizado nessas abordagens refere-se à troca do termo felicidade pela expressão satisfação subjetiva ou BES (bem-estar subjetivo) - o que nada parece acrescentar em termos de análise. Assim, "as definições desses conceitos, e consequentemente sua operacionalização em termos de medida, ainda são um pouco confusas e deturpadas. Não existe um consenso entre os estudiosos do assunto, o que dificulta a investigação do BES" (Albuquerque; Tróccoli, 2004, p. 153). As questões formuladas nestas pesquisas enfrentam muitas vezes o problema de que a felicidade é um conceito amplo, que não pode

[...] ser mensurado usando questões tão simples como estas. De fato, falar em felicidade talvez seja um pouco exagerado, por isso alguns autores preferem o termo "bem-estar subjetivo", mas mesmo assim seria válido imaginar que tal ideia não pode ser mensurada tão facilmente. Mudanças de humor, até mesmo relacionadas ao tamanho dos questionários, poderiam influenciar as respostas a perguntas tão subjetivas (Ribeiro, 2015, p. 48). 
Também Corbi e Menezes-Filho (2006, p. 520) apontam que a dificuldade de medir a felicidade é uma realidade. Destacam, porém, que esta não deve ser uma barreira para que estudos desta natureza deixem de ser conduzidos. Em uma das passagens do texto, questionam se

A felicidade pode ser medida? Desde que pesquisas de opinião começaram a ser conduzidas na década de 60, iniciou-se um grande debate metodológico. Sabemos que não podemos tentar medir a felicidade da mesma maneira que se quantifica variáveis como altura, peso e pressão arterial dos indivíduos. Observar este fenômeno diretamente está completamente fora do nosso alcance - algo difícil de ser concebido mesmo que especulativamente. A forma pela qual este tipo de estudo tem se desenvolvido nas últimas décadas, através de questionário e entrevistas aplicadas a amostras representativas de diversas sociedades, levanta inegavelmente dúvidas metodológicas legítimas e difíceis de serem respondidas, mas que, ao mesmo tempo, não desqualificam este tipo estudo, que foi uma das primeiras aproximações econômicas para o entendimento de como se determina o bem-estar subjetivo dos indivíduos.

O empenho em adicionar elementos à análise é percebido em muitos trabalhos ${ }^{5}$. A intenção de propor uma visão sistêmica é igualmente verificável na literatura, conforme apontado anteriormente. A despeito dos avanços em termos de operacionalização econométrica que estas abordagens possam promover, ganhos conceituais parecem inexistir. Para Bresser-Pereira (2014), estas inferências não são aderentes a nenhum plano político que se possa conceber:

Na minha definição de progresso não incluí a conquista da felicidade, porque esse não é um objetivo político - não é algo que possa ser alcançado coletivamente. Felicidade é um estado de espírito; é a satisfação consigo próprio que vem e vai durante toda a nossa vida. Os pesquisadores têm

\footnotetext{
${ }^{5}$ Ao destacar as possibilidades do aporte econométrico neste tema, Shikida (2008) aborda a famigerada relação entre dinheiro e felicidade. Conclui que os atributos da relação mudam de acordo com a faixa de renda: quando o indivíduo possui altas rendas, o dinheiro perderia o poder de fazer as pessoas felizes; no outro extremo, onde os recursos são escassos, mais dinheiro daria uma expressiva contribuição à felicidade das pessoas.
} 
tentado medir a felicidade, mas se é difícil medir o crescimento econômico, e mais difícil ainda medir o progresso, o que dizer da felicidade? (BresserPereira, 2014, p. 58).

Porém, como destacado anteriormente, e para aqui esboçar um entrelaçamento possível entre os enfoques, enquanto o FIB atende aos anseios de se ter um catalizador de mudanças (McLean, 2014; Tideman, 2016; Uchida; Oishi, 2016), o IFF apresenta-se como instrumento econométrico que, por suas propriedades, é sensível ao conjunto de elementos destacados na abordagem do FIB.

Interessante consideração sobre a possibilidade desta mensuração pode ser observada em trabalho recente de Antolini (2016). Para este autor, ao apontar a tese de Freud, a seguir explicitada, a mensuração da felicidade, caso realizada, prescindiria de uma análise matemática das taxas de depressão em economias modernas e industrializadas, ou seja, uma análise da infelicidade. Doenças crônicas e transtornos depressivos, para o pesquisador, estão diretamente relacionados ao estilo de vida atual - diferente e desviante daquele estilo caçador-coletor de nossos antepassados. Em consequência, a observação de que gastos com antidepressivos deveriam fazer parte de um indicador de (in)felicidade é defendida como pertinente. Uma subtração do PIB ou de um novo indicador seria o resultado desta aplicação - notadamente quanto ao uso de um indicador particular de felicidade.

Mas, enfim, qual a validade conceitual desta pretensão e do programa daí derivado? A recorrência à obra freudiana parece aqui amplamente pertinente, principalmente as reflexões e considerações contidas no texto clássico O mal-estar na civilização (Freud, [1930] 2010), na medida em que, ao colocar em evidência o psiquismo humano diante da imposição da civilização/cultura, permite relativizar a noção de felicidade. Alguns elementos relevantes são a seguir apresentados, postas a importância e a pertinência de se considerar as reflexões de tão célebre figura intelectual das ciências humanas sobre a noção de felicidade. Principalmente, quando 
tais reflexões têm sido solenemente ignoradas nas referências teóricas dos trabalhos recentes que se propõem a postular e medir a felicidade como o novo sentido para o desenvolvimento. Não se trata de esperar que esses trabalhos viessem a concordar com a perspectiva freudiana sobre a questão, mas que pelo menos a considerassem para lhes apontar os eventuais equívocos. Foucault (1987), ao comentar a fundamental contribuição de Freud para a possibilidade de novas interpretações sobre o viver humano e social, relata que este apontava para três grandes feridas no narcisismo da cultura ocidental: a ferida imposta por Copérnico ao conceber o Heliocentrismo; a estabelecida por Darwin, quando apontou que o homem descendia do macaco; e a ferida provocada por ele mesmo, Freud, quando irrecorrivelmente sustenta que a tão considerada consciência humana nasce, em última instância, do inconsciente.

\section{Um olhar freudiano sobre a felicidade}

As polêmicas sobre temas e estados eminentemente subjetivos e individuais e outros que seriam sociais e objetiváveis não são novas, e estão na origem mesma da sociologia e da sua pretensão e construção como ciência - empreendimento que teve em Durkheim um dos principais artífices, como magistralmente abordado na brilhante obra sobre o suicídio (Durkheim, 1986). Mas, se Durkheim obteve êxito ao angariar reconhecimento sobre uma dimensão que é própria do coletivo e do social, em atos e estados que eram, até então, reconhecidos somente como da alçada do psicológico e individual, conformando e legitimando assim um campo próprio para a sociologia, seu empreendimento pouco ou nada dialogou com as contribuições que seu quase contemporâneo Freud apresentou para a psicologia e para as ciências sociais. Somente após a morte de ambos é que tal diálogo foi possível, e até tornou-se prolífico em várias vertentes das ciências humanas e sociais. E, pode-se afirmar com convicção, ainda atualmente se constitui em linha de frente dos debates que buscam exercitar a interdisciplinaridade e, assim, avançar 
nos conhecimentos sobre as complexas relações entre indivíduos e suas vidas em sociedade (Oliveira, 2014) .

Portanto, sem a pretensão de tomar a abordagem freudiana como a última palavra nos debates e explicações das relações psíquicas do indivíduo com a sociedade, mas reconhecendo que ela traz reflexões que não podem ser ignoradas, principalmente sobre a noção de felicidade, vamos explicitar o que consideramos o olhar freudiano sobre o tema. Argumentaremos que, para este pensador, a noção de felicidade refere-se a um estado essencialmente transitório e subjetivo, pela própria relação que o indivíduo estabelece com a sociedade, não se prestando a fundamentar medidas e indicadores sintéticos do social.

Na obra O mal-estar na civilização, Freud ([1930] 2010) aproxima a condição humana ao âmbito social e cultural em que vivencia sua existência. O texto pode ser considerado abrangente e de elevado nível especulativo, notadamente quanto à diversidade de temas abordados e à trama estabelecida com o campo cultural, conforme apontam diversos autores (Birman, 1998; Tavares, 1993; Zavarone; Celes, 2004; Enriquez, 2005; Antolini, 2016). Não obstante, a obra parece permitir um avanço concreto que, realizado a partir de temas anteriormente tratados, pode ser compreendido como uma "generalização, para a cultura como um todo" (Mello Neto; Martínez, 2002, p. 51).

Em termos gerais, as características percebidas no texto permitem entendê-lo em um momento particular dos escritos de Freud, marcado pela inserção das abordagens anteriormente elaboradas no campo social stricto

6 Ilustrativo, nesta perspectiva, Oliveira (2014) apresenta interessante reflexão sobre a sociologia formulada por Durkheim, mais precisamente sobre a abordagem da dimensão normativa da vida social e sua relação com a individualidade dos sujeitos. Essa questão é problematizada observando-se o conceito de consciência em sua expressão coletiva e individual e os aspectos relativos às representações (eixo da cultura) e distorções da percepção (eixo do conhecimento). O confronto dos aportes teóricos de Durkheim com a teoria psicanalítica permite ao autor considerar o reducionismo sociológico de um ponto de vista crítico e analisar em que sentido os conceitos formulados por Freud podem contribuir para enriquecer o debate sobre as mediações entre a vida coletiva e o indivíduo no contexto da teoria sociológica. 
sensu. Macêdo (2012), ao destacar o conceito de desamparo, presente em momentos distintos da teoria freudiana, aponta que

A segunda dimensão, a que relaciona o desamparo à renúncia pulsional é produto do terceiro momento, com obras publicadas após 1926. Apresenta o desamparo não mais apenas como situação, mas como condição para viver em sociedade. Está relacionada à falta de garantias do sujeito sobre seu existir e sobre seu futuro, que é obrigado a uma renúncia pulsional como condição para viver em sociedade (Macêdo, 2012, p. 103).

A leitura atenta do texto de Freud permite verificar um conceito inicial que percorre todo o trabalho: o princípio do prazer. Segundo tal construção, o ser humano refuta, desde seu nascimento, a dor e o desprazer do mundo externo, livrando o seu Eu daquilo que causa sofrimento. Com sua evolução, estabelece-se o princípio da realidade, quando a separação entre o Eu e o mundo exterior fica nítida. Em suas palavras, a felicidade pode ocorrer somente esporadicamente, como um fenômeno essencialmente episódico:

Como se vê, é simplesmente o programa do princípio do prazer que estabelece a finalidade da vida. Esse princípio domina o desempenho do aparelho psíquico desde o começo; não há dúvidas quanto a sua adequação, mas seu programa está em desacordo com o mundo inteiro, tanto o macrocosmo como o microcosmo. É absolutamente inexequível, todo o arranjo do Universo o contraria; podemos dizer que a intenção de que o homem seja "feliz" não se acha no plano da "Criação". Aquilo que chamamos de "felicidade", no sentido mais estrito, vem da satisfação repentina de necessidades altamente represadas, e por sua natureza é possível apenas como fenômeno episódico (Freud, [1930] 2010, p. 30-1).

Ao considerar a felicidade como um sentimento substantivamente subjetivo, Freud aponta para a negação da possibilidade de medi-la. Nesse sentido, não se poderia comparar o sofrer de um indivíduo com o de outro, ou seja, tratar-se-ia de uma questão idiossincrática na qual o economista Jeremy Benthan, já em 1789, procurou enfrentar por meio da teoria utilitarista (ou princípio da felicidade maior). Este princípio econômico, norteador da evolução da teoria econômica neoclássica, vinculou-se 
historicamente ao propósito de interpretar o comportamento do indivíduo por meio dos domínios da dor e do prazer, tal como aqui se apresenta. A crítica ao trabalho de Benthan, assim, apoiou-se na evidente dificuldade de comparar ou mesmo agrupar a percepção de diferentes indivíduos com fins de mensuração da felicidade coletiva (Brue, 2005; Antolini, 2016). Neste contexto, em trecho mais incisivo, Freud foca sua tese em fenômenos sociais que realizam ações em torno de interesses comuns:

É de particular importância o caso em que grande número de pessoas empreende conjuntamente a tentativa de assegurar a felicidade e proteger-se do sofrimento através de uma delirante modificação da realidade. Devemos caracterizar como tal delírio de massa também as religiões da humanidade. Naturalmente, quem partilha o delírio jamais o percebe (Freud, [1930] 2010, p. 38).

A cultura cristalizada, por vezes denominada civilização, tem um destaque central em sua obra. Ela pode ser entendida como a "soma das realizações e instituições que afastam a nossa vida daquela de nossos antepassados animais, e que servem para dois fins: a proteção do homem contra a natureza e a regulamentação dos vínculos dos homens entre si" (Freud, [1930] 2010, p. 489). As realizações obtidas pela humanidade, no entanto, não constituem, para o autor, a possibilidade de se obter a felicidade, pois a evolução desta cultura aparece como "um processo peculiar que se desenrola na humanidade, no qual muita coisa quer nos parecer familiar" e a "sublimação é o destino imposto ao instinto pela civilização" (Freud, [1930] 2010, p. 58-60). Fica evidente, em sua argumentação, que a cultura gera grandes restrições e sacrifícios. No entanto, conforme apontado em McLean (2014) e Antolini (2016), o problema do significado cultural da felicidade não deve ser desprezado em estudos da área, sobretudo pelo fato de que a felicidade pode representar um estado mental $X$ em dada sociedade e $Y$ em outra.

Freud afirma que a máxima de "amar ao próximo ou ao desconhecido" é uma invenção da civilização e que, ao contrário desta assertiva, a intenção verdadeira do ser humano é bem estranha a este propósito. Para o autor, o 
ser humano não é uma criatura branda, e entre suas características instintuais pode-se detectar notadamente a agressividade. Em outra crítica, refuta o argumento comunista de que a felicidade seria possível com o fim da propriedade privada. É surpreendente - não por esta última constatação, mas sim pelas categorias de análise que emprega -, a aproximação deste autor com a linguagem liberal. Escolhas, necessidades, a ênfase no indivíduo, agressividade (autointeresse), sacrifício/restrições são alguns exemplos do conjunto de constructos ou recortes analíticos utilizados em sua obra ${ }^{7}$.

Um confronto entre humanidade e cultura surge, pois,

Se a cultura impõe tais sacrifícios não apenas à sexualidade, mas também ao pendor agressivo do homem, compreendemos melhor por que para ele é difícil ser feliz nela. De fato, o homem primitivo estava em situação melhor, pois não conhecia restrições ao instinto. [...] O homem civilizado trocou um tanto de felicidade por um tanto de segurança (Freud, [1930] 2010, p. 82).

Portanto, "em tudo o que se segue me atenho ao ponto de vista de que o pendor à agressão é uma disposição de instinto original e autônoma do ser humano, e retorno ao que afirmei antes, que a civilização tem aí o seu mais poderoso obstáculo" (Freud, [1930] 2010, p. 90).

A opressão do $E u$, a revolta deste contra si mesmo (consciência) e a consequente agressividade gerada provocam o sentimento de culpa. Esta consciência, para Freud, é, por fim, o resultado esperado da renúncia instintual. O autor demonstra, portanto, a importância de "situar o sentimento de culpa como o problema mais importante da evolução cultural e de mostrar que o preço do progresso cultural é a perda de felicidade, pelo acréscimo do sentimento de culpa" (Freud, [1930] 2010, p. 106).

A validade e a pertinência deste conjunto de elementos para o debate sobre FIB e IFF são evidentes, em especial quando se observa, em Freud, que a felicidade é um objetivo que não se pode obter (senão com realizações

${ }^{7}$ Não se realizam aqui desdobramentos desta questão que, embora pertinente, excede os limites deste trabalho. 
esporádicas). Pela constituição psíquica apresentada em seus escritos e, de outro lado, pelas imposições culturais que atuam em sociedade (e contra o ser humano), o sofrimento é a regra, não o prazer. Em certa medida, pode-se entender que um trade-off é estabelecido, pois o esforço de construção de uma unidade social (civilização) gera uma perda em termos de absorção desta unidade pelo indivíduo; uma batalha trava-se entre os instintos individuais e a civilização. Um retorno aos preceitos sobre felicidade interna bruta é aqui pertinente. O conteúdo expresso no excerto a seguir ignora e diverge da análise freudiana, carecendo justamente da crítica ao conteúdo civilizacional que encerra:

De uma forma mais geral, a descrição dos indicadores para o FIB pode ser expressa usando um ícone tradicional, a roda. No centro da roda se situa o cubo da mesma. Similarmente, a meta última do FIB é o bem-estar, a felicidade e a satisfação com a vida, aquilo que é o verdadeiro potencial na sociedade humana que buscamos atingir. Os meios para se atingir essa meta são os raios da roda. No caso do FIB, esses raios representam os domínios, tais como o raio da educação, o raio da boa saúde, o raio do uso equilibrado do tempo, o raio da cultura, o raio da boa governança, o raio da vitalidade comunitária, o raio da resiliência ecológica, e o raio do componente material da existência - o padrão de vida (FIB, 2013).

Em outro argumento, observa-se a felicidade como um traço estável do indivíduo, novamente em desacordo com o que observara Freud:

Os pesquisadores sobre felicidade da "ciência da hedônica" definem a felicidade (algumas vezes chamada de "bem-estar subjetivo") como a combinação de três aspectos: o grau e a frequência de sentimentos positivos; o nível médio de satisfação que a pessoa reporta durante um período mais alongado de tempo; e o grau de ausência de sentimentos negativos, tais como depressão. Essa forma de definir a felicidade estabelece que a mesma deve ser um traço estável no indivíduo, e não uma momentânea flutuação. Logo, a felicidade não é meramente definida como a ausência de sentimentos negativos, mas também a presença de sentimentos positivos (FIB, 2013).

O que se evidencia, portanto, são consideráveis divergências entre as concepções. As restrições impostas ao indivíduo, os sacrifícios por 
ele enfrentados e, portanto, sua condição diante da civilização é, em Freud, uma orientação particular que em muito destoa da abordagem do desenvolvimento baseado na felicidade, como proposto nos trabalhos presentes em FIB (2013) e mesmo em outros com diferentes referenciais, mas com similar proposição. Assim, pelo que apresentamos e que se constitui no móvel que nos levou a tecer estas reflexões, é que acreditamos que não há razão para que as contribuições de uma figura com a estatura intelectual de Freud sejam desprezadas ou solenemente ignoradas pelas abordagens que buscam a mensuração e utilização do conceito de felicidade para ressignificar o sentido contemporâneo de desenvolvimento. Cremos que não existem motivos plausíveis para que este debate não esteja suficientemente contemplado nas reflexões sobre este tema ${ }^{8}$.

\section{Considerações finais}

O desfecho das questões aqui propostas implica a necessidade de se tentar tecer algumas reflexões finais, mesmo que provisórias. Está muito clara a intenção de reforma dos índices convencionais de crescimento e desenvolvimento, incorporando-se índices mais sistêmicos que avancem em termos econométricos. Parece haver forte consenso sobre esta questão na literatura consultada, apresentando-se a pesquisa do IFF muito sensível ao conjunto de elementos destacados na abordagem do FIB. Neste caminho, pôde ser detectado um agrupamento de noções que orbita no que se reconhece como a atual abordagem territorial do desenvolvimento, o que gera duas questões: (a) o programa aponta para elementos já construídos em outras abordagens, o que não se traduz em algo inovador em termos de abordagem integral do desenvolvimento; e, ao utilizar-se de tais elementos, (b) apresenta

\footnotetext{
${ }^{8}$ Pode-se questionar se o debate freudiano, nos termos aqui colocados, deveria estar contemplado por quem discute o assunto em nível de políticas públicas com vistas ao desenvolvimento; mas cremos que as considerações de Freud sobre o sentimento de felicidade humana, no mínimo, deveriam provocar dilemas para quem busca planejar/ programar o mundo social e econômico, antes que ineludíveis certezas matemáticas tão pouco confiáveis nos históricos sobre o tema.
} 
baixa densidade teórica, inclinando-se muitas vezes a um conteúdo prescritivo próximo ao sentido de tutela. Fica explícito que o uso de elementos já trabalhados em outras abordagens traz um uso mais mecânico que conceitual; mais matemático que subjetivo; mais normativo que explicativo; enfim, o uso econométrico daqueles conceitos é o destaque central deste programa.

Uma análise conceitual da felicidade foi aqui oferecida por meio do olhar existencialista freudiano. A relativização deste conceito pode ser um tanto intuitiva (Kahneman; Krueger, 2006); sua relação com a cultura, porém, não o é. Freud permite pensar esta relação como um dilema, um trade-off entre o que o psiquismo humano demanda e o que a cultura Ihe pode dar. Esta é a tese central do texto aqui trabalhado, contribuição esta que estranhamente não vem sendo considerada nas recorrentes abordagens do FIB e do IFF como proposições de renovados sentidos para o desenvolvimento - possivelmente pela ainda forte prevalência do econométrico sobre o conceitual. Parece-nos que este duelo entre o princípio do prazer e o princípio da realidade remete a felicidade a certa insustentabilidade (a ela também inerente), questão esta não observada nos programas FIB-IFF relacionados à noção de desenvolvimento. Assim, os sacrifícios e restrições impostos ao indivíduo pela civilização teriam necessariamente que ser considerados em (novas) abordagens que postulam consolidação e reconhecimento teóricos ${ }^{9}$. Ademais, todo esforço de tutela que se possa empregar nas abordagens do FIB e do IFF pode concorrer muito mais para vitalizar o status quo civilizacional, com suas mazelas e insuficiências, do que construir as bases de uma vida melhor.

\footnotetext{
${ }^{9}$ Um tema que parece ter conexão analítica promissora com o que foi aqui abordado, é a importante discussão sobre o "bem viver" (buen vivir), tema polêmico, mas que tem crescentemente atraído pesquisadores por ter uma característica nativa e que se opõe à noção universalista do desenvolvimento. Este tema busca se articular em torno dos diversos sentidos do que seja viver bem nas diferentes experiências etnoculturais que têm lugar nos amplos e diversos territórios da América Latina. Todavia, é tema para se abordar em outro momento analítico, merecedor de tempo e reflexão próprios e adequados.
} 


\section{Agradecimentos}

Os autores agradecem o auxílio do CNPq e as contribuições dos pareceristas e do Grupo de Estudos em Organizações e Desenvolvimento (GEODes) da Universidade Federal do Pampa.

José Marcos Froehlich é doutor em Ciências Sociais em Desenvolvimento, Agricultura e Sociedade pela UFRRJ e Professor Associado da Universidade Federal de Santa Maria e bolsista de produtividade em pesquisa do CNPq.

$\doteq$ jmarcos.froehlich@gmail.com

Mauro Barcellos Sopeña é doutor em Extensão Rural e Desenvolvimento pela UFSM e Professor Adjunto da UNIPAMPA.

$\doteq$ maurosopena@unipampa.edu.br

\section{Referências}

1. ABRAMOVAY, R. Para uma teoria dos estudos territoriais. In: Ortega, A.; Almeida Filho, N. (org.). Desenvolvimento territorial, segurança alimentar e economia solidária. Campinas: Alínea Ed., 2007.

2. ALBUQUERQUE, A.; TRÓCCOLI, B. Desenvolvimento de uma escala de bemestar subjetivo. Psicologia: Teoria e Pesquisa, v. 20, n. 2, p. 153-64, maio 2004.

3. ANTOLINI, F. The Evolution of National Accounting and New Statistical Information: Happiness and Gross Domestic Product, Can We Measure It? Social Indicators Research, v. 129, n. 3, p. 1075-92, 2016.

4. BAGNASCO, A. A teoria do desenvolvimento e o caso italiano. In: ARBIX, G.; ZILBOVICIUS, M. Razões e ficções do desenvolvimento. São Paulo: UNESP, 2001.

5. BENTHAM, J.; MILL, J.S. Uma introdução aos princípios da moral e da legislação. São Paulo: Abril Cultural, 1979.

6. BIRMAN, J. O mal-estar na modernidade e a psicanálise: a psicanálise à prova do social. Physis - Revista de Saúde Coletiva, Rio de Janeiro, v. 8, n. 1, p. 203-24, 1998.

7. BRESSER-PEREIRA, L. C. Desenvolvimento, progresso e crescimento econômico. Lua Nova, São Paulo, v. 93, p. 33-60, 2014.

8. BRUE, S. História do pensamento econômico. São Paulo: Thomson, 2005.

9. CECHIN, A. Georgescu-Roegen e o desenvolvimento sustentável: diálogo ou anátema? 2008. Dissertação. Programa de Pós-Graduação em Ciência Ambiental da Universidade de São Paulo.

10. CORBI, R.; MENEZES-FILHO, N. Os determinantes empíricos da felicidade no Brasil. Revista de Economia Política, v. 26, n. 4 (104), p. 518-36, out/dez 2006. 
11. COWEN, M.; SHENTON, R. Doctrines of development. Londres, Routledge, 1996.

12. CRUSH, J. Power of development. Londres: Routledge, 1996.

13. DURKHEIM, E. Le suicide. Paris: PUF, 1986.

14. ENRIQUEZ, E. Psicanálise e ciências sociais. Ágora, Rio de Janeiro, v. VIII, n. 2, p. 153-74, 2005.

15. FEIJÓ, C. et al. Além do PIB: uma visão crítica sobre os avanços metodológicos na mensuração do desenvolvimento socioeconômico e o debate no Brasil contemporâneo. Estatística e Sociedade, Porto Alegre, p. 42-56, n. 2, 2012.

16. FIB. Desenvolvimento. In: FIB - Felicidade interna bruta. 2013. Disponível em: <http:// http://www.felicidadeinternabruta.org.br/>. Acesso em: 23 jul. 2013.

17. FOUCAULT, M. Theatrum Philosoficum. 4ae ed. São Paulo: Editora Princípio, 1987. 18. FRANCO, G. Índices de Felicidade e Desenvolvimento Econômico. Apresentado no Ciclo de Conferências O próximo futuro: grandes lições. Lisboa: Fundação Calouste Gulbenkian, 16 nov. 2011.

19. FREUD, S. O mal-estar na civilização. Trad. Paulo C. Souza. São Paulo: Editora Schwarcz, [1930] 2010.

20. FROEHLICH, J. M. O local na atribuição de sentido ao desenvolvimento. Revista Paranaense de Desenvolvimento, Curitiba, v. 1, n. 1, p. 65-84, 1999.

21. FURTADO, C. O mito do desenvolvimento econômico. Rio de Janeiro: Paz e Terra, 1974.

22. GREVE, B. Felicidade. São Paulo: Editora Unesp, 2013.

23. KAHNEMAN, D.; KRUEGER, A. Developments in the measurement of subjective well-being. Journal of Economic Perspectives. v. 20, n. 1, p. 3-24, dez/fev, 2006.

24. KAFKA, F. Um artista da fome / A construção. Tradução de Modesto Carone. São Paulo: Companhia das Letras, 1998.

25. MACEDO, K. O desamparo do indivíduo na modernidade. ECOS. v. 2, n. 1, p. 94-107, 2012.

26. MCLEAN, D. National and International Indices of Well-being: A Critical Analysis. Journal of the Indiana Academy of the Social Sciences, v. 17, n. 1, p. 39-54, 2014.

27. MARQUES JUNIOR, L.; PÔRTO JUNIOR, S. O método da teoria neoclássica a economia neoclássica é uma teoria refutável? In: G. CORAZZA (Org.). Métodos da Ciência Econômica. Porto Alegre: Editora da UFRGS, 2003.

28. MELLO NETO, G.; MARTíNEZ, V. Angústia e sociedade na obra de S. Freud. Psicologia em Estudo, Maringá, v. 7, n. 2, p. 41-53, 2002. 
29. NERI, M. (Org.). Jovens, educação, trabalho e o índice de felicidade futura. Centro de Políticas Sociais, Rio de Janeiro: FGV/IBRE, 2008.

30. NERI, M. A nova classe média: o lado brilhante da base da pirâmide. São Paulo: Ed. Saraiva, 2011.

31. O ESTADO DE SÃO PAULO. Venezuela cria vice-ministério para a Suprema Felicidade Social. Disponível em: < http://www.estadao.com.br/ noticias/internacional,venezuela-cria-vice-ministerio-para-a-suprema-felicidadesocial,1089677,0.htm>. Acesso em 2 abr. 2014.

32. OLIVEIRA, J. M. Da consciência comportada à dialética da existência: um confronto de Durkheim e Freud. São Paulo: Scortecci Editora, 2014.

33. PUTNAM, R. Comunidade e democracia: a experiência da Itália moderna. 3‥ Ed. Rio de Janeiro, FGV, 2003.

34. RIBEIRO, C. A. Renda, Relações Sociais e Felicidade no Brasil. Dados - Revista de Ciências Sociais, Rio de Janeiro, v. 58, n. 1, p. 37-78, 2015.

35. ROJAS, C. Desenvolvimento social e intervenção estatal. XII Seminário Internacional de Demandas Sociais e Políticas Públicas na Sociedade Contemporânea. Anais... UNISC-CEPEJUR. 2015

36. SHIKIDA, P. F. A. A gente não quer só dinheiro... a gente quer dinheiro e felicidade: notas e reflexões no contexto da Ciência Econômica. Ciências Sociais Aplicadas em Revista, Cascavel, v. 8, p. 47-60, 2008.

37. SOUZA, M. Algumas notas sobre a importância do espaço para o desenvolvimento local. Território, Rio de Janeiro, ano II, n. 3, p. 13-35, jul/dez. 1997.

38. TAVARES, H. Polêmica de Marcuse com Freud em torno da felicidade: Freud a felicidade no mal-estar. Síntese Nova Fase, v. 20, n. 60, p. 51-65, 1993.

39. TIDEMAN, S. Gross National Happiness: lessons for sustainability leadership. South Asian Journal of Global Business Research, v. 5, n. 2, p. 190-213, 2016.

40. VASCONCELLOS, M. Fundamentos de economia. São Paulo, Saraiva, 2008.

41. UCHIDA, Y.; OISHI, S. The happiness of individuals and the collective. Japanese Psychological Research, v. 58, n. 1, p. 125-41, 2016.

42. VEIGA, J. Desenvolvimento sustentável - desafio do século XXI. Rio de Janeiro: Garamond, 2005.

43. VEIGA, J. Sustentabilidade: a legitimação de um novo valor. Rio de Janeiro: Ed. Senac, 2010.

44. ZAVARONI, D.; CELES. L. O processo civilizador: uma leitura da pulsão de morte como excessivo pulsional na compreensão freudiana da cultura. Pulsional - Revista de Psicanálise, ano XVII, n. 179, p. 66-77, 2004. 